\title{
Review and investigations on geothermal energy extraction from abandoned petroleum wells
}

\author{
D. Sui ${ }^{1} \cdot$ E. Wiktorski ${ }^{1} \cdot$ M. Røksland ${ }^{1} \cdot$ T. A. Basmoen ${ }^{1}$
}

Received: 16 October 2017 / Accepted: 10 June 2018 / Published online: 25 August 2018

(c) The Author(s) 2018

\begin{abstract}
Geothermal energy is a sustainable and renewable energy source, which can be used in electricity production, space heating/cooling, and other industrial applications. In the recent years, it has been gathering more and more attention due to its numerous advantages as low impact on the surrounding environment, continuous power outputs, low greenhouse gas emissions, and worldwide availabilities. All make the geothermal energy a significant contributor to the global energy productions in an environmentally friendly way. One big concern of geothermal sources' exploration is the expensive investment costs of geothermal wells. Utilizing abandoned petroleum wells for the purpose of geothermal extraction is a novel idea. Well temperature profiles help to estimate how much heat can be transferred and produced from the wells. In this paper, a literature review has been done to investigate the existing applications on geothermal energy extraction utilizing abandoned petroleum wells. Then, the case study demonstrates the importance of properties of working fluids, wellbore architecture, and operational parameters (circulation rate, inlet temperature, etc.) in geothermal energy production. The obtained results can be used to achieve an improved data interpretation and generate more optimal solutions. In geothermal projects, extensive knowledge of the heat transfer is of great importance for the economical aspect and the performance of wells. Our work demonstrates that it is a good approach to provide cost-effective solutions to enhance heat extraction from geothermal wells.
\end{abstract}

Keywords Geothermal energy $\cdot$ Abandoned petroleum wells $\cdot$ Heat transfer

\section{Geothermal energy}

As the pollution and emissions from today's industry continue to have negative environmental impacts, renewable and clean energy sources become more and more attractive. Utilizing renewable energy sources provides a clean alternative to the environmental damaging energy sources and helps to mitigate the climate changes. Due to its unlimited supply, energy production from geothermal resources has become a potential contender. Electricity production from geothermal sources has grown substantially for the past 20-25 years with an increase of the installed generating capacity from 1300MW in 1975 to $10715 \mathrm{MW}$ in 2010 (Bu et al. 2012).

Geothermal energy is considered one of the most promising and reliable energy resources. It is barely affected by weather and available for operation $98 \%$ of the time

D. Sui

dan.sui@uis.no

1 Petroleum Engineering Department, University of Stavanger, 4036 Stavanger, Norway
(Templeton 2013), which provides a reliable and steady output. Future growth is expected that geothermal energy could meet more than $3 \%$ of global electricity demand by 2050 (Geothermal 2018). Geothermal energy has various applications in the modern society. High-temperature geothermal resources (above $150{ }^{\circ} \mathrm{C}$ ) are usually used to produce electricity (Barbier 2002). Low-temperature resources (below $150^{\circ} \mathrm{C}$ ) are used for direct space heating, dehydration of food, drying of timber, etc. Mock et al. (1997). The most typical applications of geothermal energy worldwide are listed in Lund and Boyd (2015).

A major part of the geothermal energy production today exploits energy from high-temperature resources, which are often reached by penetrating aquifers at 1000-2000 $\mathrm{m}$ below the surface to extract heat for geothermal power plants (Davis and Michaelides 2009). As most of the hightemperature resources have already been exploited, a further expansion of production has to come from lower temperatures resources. One of the main challenges of geothermal sources' exploration is the expensive investment costs of geothermal wells. Abandoned petroleum wells located in 
areas with steep geothermal gradients may be a good and cheap alternative for geothermal energy production from relatively low-temperature resources. In the next section, we provide a detailed review of scientific research work of utilization of abandoned wells for geothermal energy extraction, estimation of potential for heat production and parametric study.

\section{Literature review}

Abandoned wells come with several features that are desirable for geothermal energy production. Clauser and Ewert (2018) showed that the geothermal energy is one of the most cost-effective ways in energy production, which, however, comes with high investment costs. Drilling a geothermal well is usually time-consuming and expensive, in the same way as drilling a petroleum well. By making use of an already drilled petroleum well, huge amount of costs can be saved. In Bu et al. (2012), the major cost is reduced by $50 \%$ when using an existing well. Existing wells also offer the opportunity to extend length of drilled wells to a deeper depth or drill a lateral to access improved thermal conditions or geothermal reservoirs farther away at a lower cost. In addition, providing further use of abandoned wells can eliminate liabilities related to plug and abandonment, because abandoning a well is a high-cost process. In consequence, most wells are done at the minimal cost and they meet the minimal obligations set by regulating agencies. Offering the chance to lower these costs by converting petroleum wells to geothermal wells will save a lot of investment costs for heat extraction.

Exploiting geothermal energy from abandoned wells requires that wells are retrofitted into heat exchangers. A great part of these studies are devoted to open-loop systems. The purpose of an open-loop system is to use the oil or gas reservoir as a groundwater geothermal reservoir. Open-loop systems consist of at least one injection well and one extraction well. A fluid is pumped through an injection well into a reservoir, where it gains heat from surrounding rocks before it is circulated through an extraction well. Many researchers (Kujbus 2007; Wei et al. 2009; Reyes 2007; Kurevija and Vulin 2011; Lund et al. 2005, 2011; Kharseh et al. 2015; Barbacki 2000) have recently carried out these studies from the economical and practically feasible perspective.

Another possibility is to convert a well into a heat exchanger using a closed-loop system (Bu et al. 2012; Templeton 2013; Davis and Michaelides 2009; Templeton et al. 2014; Sanyal and Butler 2010; Kujawa et al. 2005; Ghoreishi-Madiseh et al. 2012), where a single well is required. An abandoned oil well can be retrofitted to a closed-loop system by installing either a U-tube or a double-pipe heat exchanger. A U-tube heat exchanger has a characteristic bend at the bottom connecting two parallel tubes. A double-pipe heat exchanger is installed into a wellbore by lowering a single tube of inferior size. One method of operating this system is to circulate working fluids downwards through an annulus and up through installed pipes. Such circulation gives fluids in the annulus sufficient time to gain heat conducted from surrounding rocks and transfer thermal energy back to the surface.

There are a great number of published scientific articles that model heat transfer in abandoned petroleum wells, estimate the potential of heat production, and perform sensitivity study to determine the optimal conditions for operating the geothermal wells. Kujawa et al. (2005, 2006) investigated the theoretical possibility of acquiring energy from a vertical well. They developed a computational temperature model to determine the amount of geothermal heat flux that can be gained using a double-pipe heat exchanger. The calculations were performed for three cases: perfectly insulated pipe, air-gap insulation formed by the casing pipes, and insulation of the polyurethane foam. They also varied the flow rate and the inlet temperature of the injected water, and found out that lower inlet temperature and higher flow rate increase the amount of the heat power of a geothermal intake.

Davis and Michaelides (2009) estimated the geothermal power production from abandoned oil wells in South Texas region using a double-pipe heat exchanger. Their mathematical temperature model was developed based on the mass, energy, and momentum conservation. In simulations, Davis and Michaelides selected isobutene as the heat-transferring fluid, which has better thermodynamic properties and, therefore, is better suited for the heat extraction. Other important assumptions of this study are the high geothermal gradient (typical for the geological area) and 1-inch-thick pipe polystyrene insulation. Their calculations show that such wells could produce more than $3 \mathrm{MW}$ from each when the bottomhole temperature is approximately $450 \mathrm{~K}$ and the injection pressure is $30 \mathrm{bar}$. They also concluded that the amount of extracted power depends on the downhole temperature, the injection pressure, fluid velocity, pipe size, and thickness of the pipe insulation.

Similar to the abovementioned works, Bu et al. (2012) developed a mathematical model to describe heat exchange between fluids and rocks and solved it numerically using tri-diagonal matrix algorithm. Unlike the model presented in Davis and Michaelides (2009), the model developed by $\mathrm{Bu}$ et al. (2012) does not include the mass conservation, since heat transfer underground occurs without mass transfer. They showed that the energy production from abandoned petroleum wells depends greatly on fluid flow rate and the geothermal gradient of formation. They conducted heat transfer analysis over circulation time and concluded that 
the outlet temperature does not vary with circulation time significantly.

Ghoreishi-Madiseh et al. (2012) simulated heat transfer in U-tube heat exchangers installed in former abandoned wells. The authors used finite volume discretization to solve the equations of mass, energy, and momentum conservation. They determined that for a typical U-tube heat exchanger, the natural convection can be neglected if the conductivity of the heat exchange medium is smaller than some specific value. They also found that the thermal and hydraulic conductivity of the medium and the rate of heat extraction are the most important parameters to affect the performance of U-tube heat exchangers in wells. In Ghoreishi-Madiseh et al. (2014), the authors further studied the sustainability of a long-term heat extraction from the abandoned petroleum wells. They concluded that it is dependent on the balance between the extraction rate and natural process of replacement of the geothermal heat in the reservoir.

Templeton et al. (2014) examined the possibility of extracting heat from the abandoned petroleum wells equipped with heat exchangers by analyzing the underground heat transfer. They used the Fourier's three-dimensional heat equation to describe the heat conduction through rocks and fluids and solved the equation using finite-element software (FlexPDE). They estimated that the well would be able to produce $80 \mathrm{KW}$ of power. The authors also carried out the parametric analysis and discovered the optimum inflow temperature and mass flow rate. Their results were compared with results presented in Kujawa et al. (2005) and Bu et al. (2012). They concluded that overestimated values for heat power were presented in both compared papers.

Cheng et al. (2013) simulated an abandoned oil well as a source of geothermal power. They prepared a model based on the transient formation heat transfer, the fluid momentum, and energy equation. Isobutene was used as a circulating fluid. They concluded that the outlet temperature of fluid decreases with time and stabilizes as the system approaches thermal equilibrium. This time can be reduced by increasing the formation thermal conductivity or decreasing fluids inlet velocity, while the heat capacity of the formation has a minor effect. In another paper, Cheng et al. (2014) presented a geothermal power generation model based on the transient formation heat transfer. Their calculations showed that the depth of an abandoned petroleum well has to be at least 3000 $\mathrm{m}$ to supply sufficient output power. They also conducted a study of various organic fluids as working fluids and recommended the working fluids to enhance the geothermal energy extraction from the abandoned oil wells.

Wight and Bennet (2015) evaluated the use of abandoned petroleum wells to extract the geothermal heat using water as the working fluid. They calculated that a power of $109 \mathrm{KW}$ could be generated from a $4200 \mathrm{~m}$ deep well located in Texas with the mass flow rate of $2.5 \mathrm{~kg} / \mathrm{s}$. They also showed that the power output increases with the mass flow rate; however, this requires deep wellbore depth to obtain sufficient fluid temperature.

Alimonti et al. (2016) used a numerical temperature model to estimate a theoretical amount of heat extracted from abandoned petroleum wells in the Villafortuna Trecate oilfield. They considered two types of working fluids: water and diathermic oil, and analyzed different internal pipe diameters to optimize the geometrical configuration for effective heat extraction. They concluded that the best heat working fluid is water. Alimonti and Soldo also determined that a pseudo-stationary condition with reduction of initial power of $45 \%$ would be attained after 5 years of exploitation.

Ahmadi and Dahi Taleghani (2016) performed numerical study using the finite-element method to estimate the potential heat extraction for fractured reservoir using highly thermal-conductive proppants in closed-loop system. Their simulations showed that more heat can be extracted from the fractured wellbores due to increased contact area between the wellbore and formation.

In general, the heat transfer process is complicated and highly dependent on fluid temperature, formation temperature gradient, circulation rate, pipe material, heat conductivity of the formation, pipe wall and working fluids, etc. A mathematical heat energy model is necessarily required to estimate the amount of geothermal energy extracted from an abandoned petroleum well. The sensitivity analysis shall be carried out to provide valuable knowledge on construction design, fluid properties, geological conditions, etc. which heavily affect the amount of extracted heat. It is helpful to verify current static data, calculate energy production, analyze effects from different parameters, and optimize profits from energy extraction.

\section{Heat transfer process of wellbores}

Heat transfer is defined as thermal energy in transit due to a spatial temperature difference to temperature differences (Bergman et al. 2011). As long as the temperature of wellbores and formations are unequal, energy exchange will take place, and the internal energy of the objects will change. Two dominate modes, conduction and convection transferred in wellbores during heat extraction process, are briefly discussed below.

\section{Conduction}

Conduction can be defined as the transfer of heat energy through direct contact between substances (solids or stationary fluids) in which there exists a temperature gradient. The heat flux by conduction in the $x$-dimension, or rate of heat transferred per unit area, $q_{x}$, through a plane wall is given as

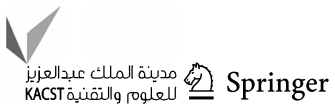


$q_{x}=-k \frac{\mathrm{d} T}{\mathrm{~d} x}$

where $\frac{\mathrm{d} T}{\mathrm{~d} x}$ is the temperature gradient in $x$-direction, and $k$ is the thermal conductivity of the substance, known as the transport property of the substance. This equation is also known as Fourier's law of heat conduction. The negative sign implies that the direction of heat flow is from hot to cold along the temperature gradient.

\section{Convection}

Convection is the transfer of heat between two surfaces by a fluid in motion through molecular interaction. The heat transfer mechanisms involved are diffusion, as for conduction, and advection, which is energy transfer through fluid bulk movement if a temperature gradient is present. The convective heat flux, $q$, is given by

$q=h\left(T_{\infty}-T_{\mathrm{s}}\right)$,

where $T_{\infty}$ is the temperature of the free stream outside the velocity boundary layer, and $T_{\mathrm{s}}$ is the temperature of the surface on which convection is considered. Here a new term, $h$, is introduced as convective heat transfer coefficient (CHTC), which depends upon the geometry of the system, the thermodynamic properties of the fluid, the thermal properties of the solid medium and the systems boundary conditions. It can be determined using the Nusselt number $N_{u}$ as

$h=\frac{k N_{u}}{D}$

where $D$ is the equivalent diameter. The relationship between convection and conduction for fluid flow through circular tubes, where there exists a temperature difference between the flowing fluid temperature and the tube walls, may be estimated through correlations obtained experimentally. Such correlations have been identified for various flow conditions and geometry. The most common correlations for forced convection in circular tubes are presented below, both for turbulent and laminar flow regimes. In Table 1, the Prandtl number $\operatorname{Pr}$ is the ratio of momentum diffusion rate to thermal diffusion rate. $R e$ is the Reynold's number which predicts the flow behavior of the fluid, or rather the onset of laminar, transitional or turbulent flow. The laminar region is for $R e \leq 2300$, the transitional region is for $2300<R e \leq 4000$, and the turbulent region is for $R e>4000$.

\section{Heat governing equations}

Calculation of temperature distribution provides a good way to investigate heat exchangers in geothermal wells. Several heat transfer models have been developed in the last decades (Feng 2011; Santoyo-Gutirrez 1997; Livescu and Wang 2014; Kabir et al. 1996; Karstad 1999; Roksland et al. 2016). In this study, to be able to calculate temperatures at any given time and depth, one energy model is formulated based on the model presented in Santoyo-Gutirrez (1997). By applying concepts and assumptions [more details of assumptions are given in Santoyo-Gutirrez (1997)], the energy equation in cylindrical coordinates is expressed below:

$\rho C_{p}\left(\frac{\partial T}{\partial t}+v_{r} \frac{\partial T}{\partial r}+v_{z} \frac{\partial T}{\partial z}\right)=-\left(\frac{1}{r} \frac{\partial\left(r q_{r}\right)}{\partial r}+\frac{\partial q_{z}}{\partial z}\right)$

where $\rho$ is the density, $C_{p}$ is the specific heat capacity, $r$ is the radius, $z$ is the depth, $t$ is time, $v_{r}$ is the linear velocity in radial direction, $v_{z}$ is the linear velocity in axial direction, $q_{r}$ is the conduction heat flux in radial direction, and $q_{z}$ is the conduction heat flux in the axial direction. By making use of the heat flux definitions (1) as

$q_{r}=-k \frac{\partial T}{\partial r}$

$q_{z}=-k \frac{\partial T}{\partial z}$

it is easy to get:

$\rho C_{p}\left(\frac{\partial T}{\partial t}+v_{r} \frac{\partial T}{\partial r}+v_{z} \frac{\partial T}{\partial z}\right)=\frac{k}{r} \frac{\partial T}{\partial r}+k \frac{\partial^{2} T}{\partial r^{2}}+k \frac{\partial^{2} T}{\partial z^{2}}$.
Table 1 Various forced convection correlations for circular tubes (Bergman et al. 2011)

\begin{tabular}{lll}
\hline Nusselt correlation & Author & Flow conditions \\
\hline$N_{u}=0.023 \operatorname{Re}^{4 / 5} \operatorname{Pr}^{n}$ & Dittus and Boelter (1930) & $0.7 \leq \operatorname{Pr} \leq 160$ \\
$N_{u}=0.027 \operatorname{Re}^{4 / 5} \operatorname{Pr}^{1 / 3}\left(\frac{\mu}{\mu_{s}}\right)^{0.14}$ & Seider and Tate (1936) & $0.7 \leq \operatorname{Pr} \leq 16000$ \\
$N_{u}=\frac{(f / 8)(\operatorname{Re}-1000) \operatorname{Pr}}{1+12.7(f / 8)^{1 / 2}\left(\operatorname{Pr}^{2 / 3}-1\right)}$ & & $\operatorname{Re} \geq 10000$ \\
$N_{u}=4.36$ & Gnielinski (1976) & $0.5<\operatorname{Pr}<2000$ \\
\hline
\end{tabular}




\section{Wellbore heat transfer}

We look into the possibility of retrofitting a double-pipe heat exchanger to an abandoned petroleum well. A working fluid circulates and gathers the heat energy from deep beneath the surface, and carries it up for further utilization. As the decommissioned petroleum well already is plugged, casings are set and the wellbore is defined, a smaller diameter pipe is installed to create a closed-loop system for circulating the fluid. This pipe, called a geostring, is essential in transportation of the fluid. Figure 1 shows the whole heat transfer process. Cold working fluid is injected into the annulus from surface. The working fluid in the annulus gains heat conducted from the formation, as it moves downwards until the end of the outer pipe. Once the heated fluid goes inside the inner pipe, it is circulated to the surface again. In this way, the geothermal energy is extracted from the formation to the surface. The inner pipe is insulated to prevent heat loss as the warmer fluid flows upwards through zones with lower temperatures.

To be able to estimate outlet temperatures of extracted fluids properly, it is highly convenient to consider the separated working regions. As the fluid experiences different influences during a full circulation, it is important to identify which influences are of importance in different scenarios. In turn, each part will influence the wellbore temperature, fluid temperature, casing temperature, etc. Therefore, in our study, the system is divided into five regions: (1) drill pipe (geostring), (2) drill pipe wall (geostring wall), (3) annular region, (4) interface between the annulus and the formation, and (5) formation. The numerical method to solve Eq. (7) is described in Appendix A with the flow chart.

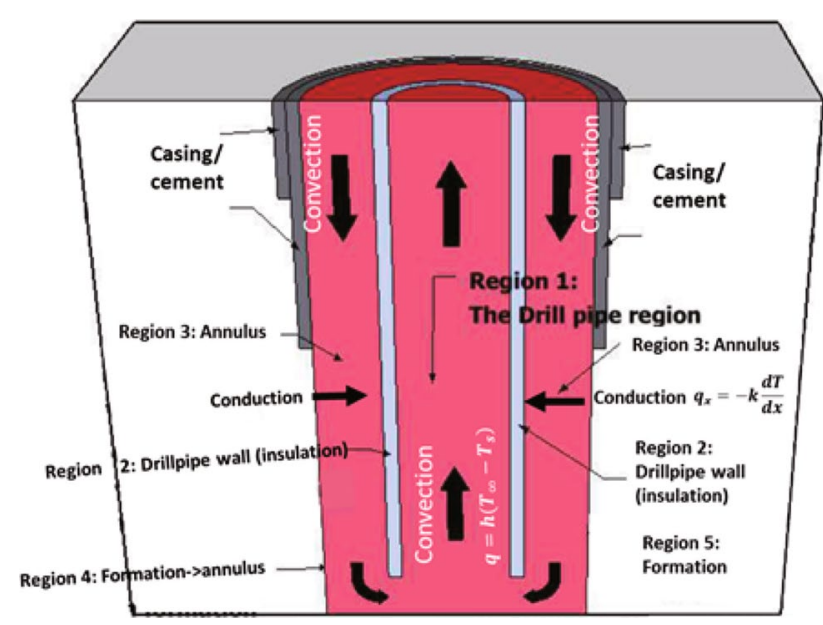

Fig. 1 Wellbore schematic

\section{Accumulated heat energy}

For estimation of heat energy $Q$ gained by the circulating fluid due to temperature differences, the following equation is used:

$Q=\dot{m} C_{p} \Delta T=\dot{m} C_{p}\left(T_{\text {out }}-T_{\text {in }}\right)$,

where $m$ is the fluid mass, $T_{\text {in }}$ is the inlet temperature of working fluid injected to the annulus, $T_{\text {out }}$ is the outlet temperature of working fluid circulated out of the geostring, and $\Delta T$ is the temperature difference between the outlet temperature and the inlet temperature.

\section{Case study}

The parameters used for the case study are given in Appendix B. In this section, a sensitivity analysis is conducted to gain a better understanding of which the configuration parameters have a critical impact on the accumulated heat energy. The simulations are based on the comparison of both the outlet temperature of the extracted fluids and the heat accumulated from the well calculated by Eq. (8). In the sensitivity analysis, one parameter is varied over a reasonable range, while the rest are kept at the defined values, as given in Table 2. The parameters chosen for the analysis are the density of the working fluids, the thermal conductivity of the working fluids, the specific heat capacity of the working fluids, the viscosity of the working fluids, the inlet temperature of the working fluids, the effect of insulation, and geostring diameter.

\section{Working fluids}

\section{Density}

It is easy to see that the density has very little effect on the outlet temperature. The trend is consequent towards lighter fluid, which exhibits a slightly higher outlet temperature, as presented in Fig. 2. It was observed that the density increase from $800 \frac{\mathrm{kg}}{\mathrm{m}^{3}}$ to $1600 \frac{\mathrm{kg}}{\mathrm{m}^{3}}$ represents a difference of only $1.96^{\circ} \mathrm{C}$. It means that the $100 \%$ difference in fluid's density causes a decrease in the outlet temperature of $2.48 \%$. The heat energy also decreases with density in a similar trend as the output temperature.

\section{Thermal conductivity}

The thermal conductivity is defined as a material's ability to conduct heat. Figure 3 illustrates that an increase in the thermal conductivity causes the increase of the heat exchange between the working fluid and the formation. 


\section{Density of fluid}

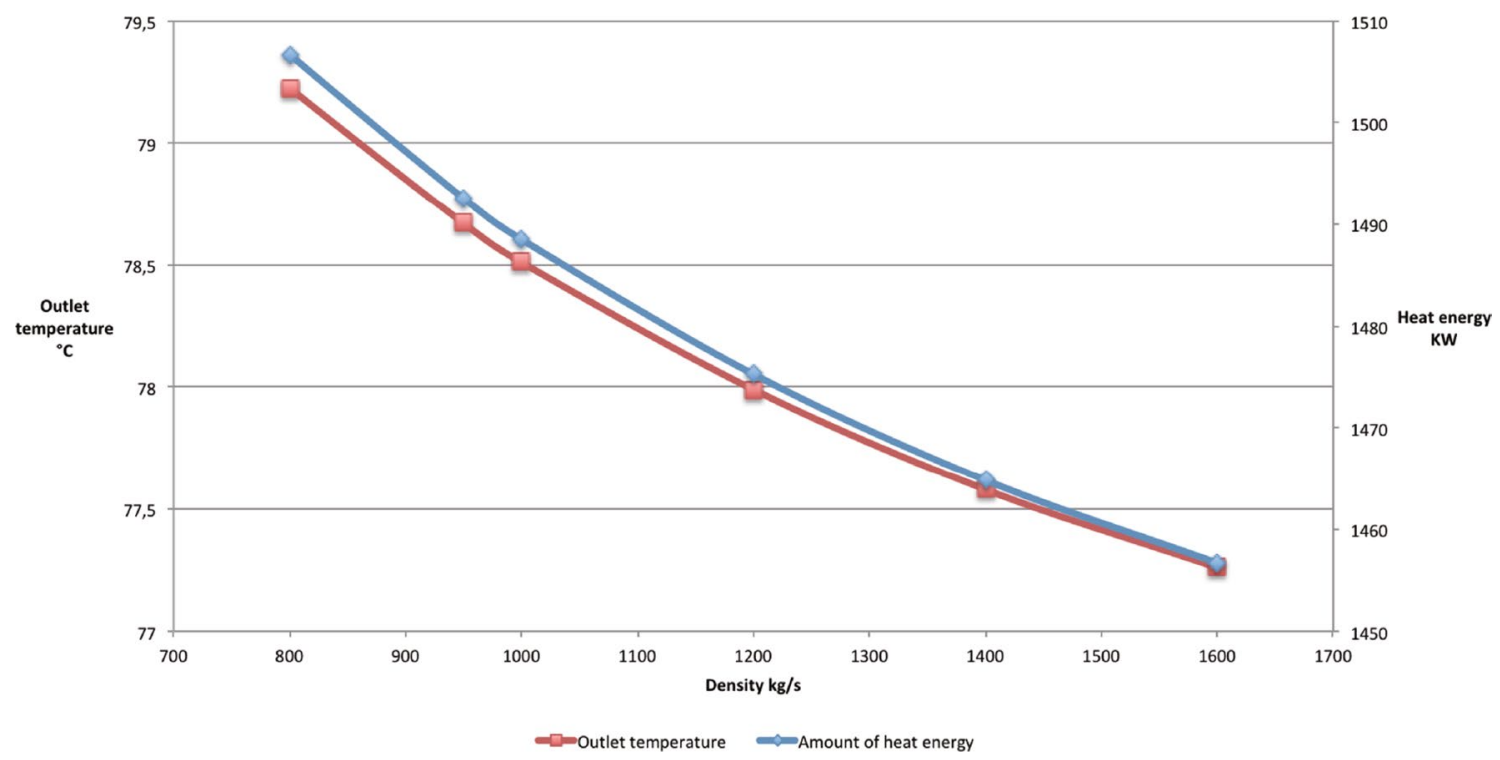

Fig. 2 Temperature and heat energy regarding working fluids' densities

Thermal conductivity of fluid

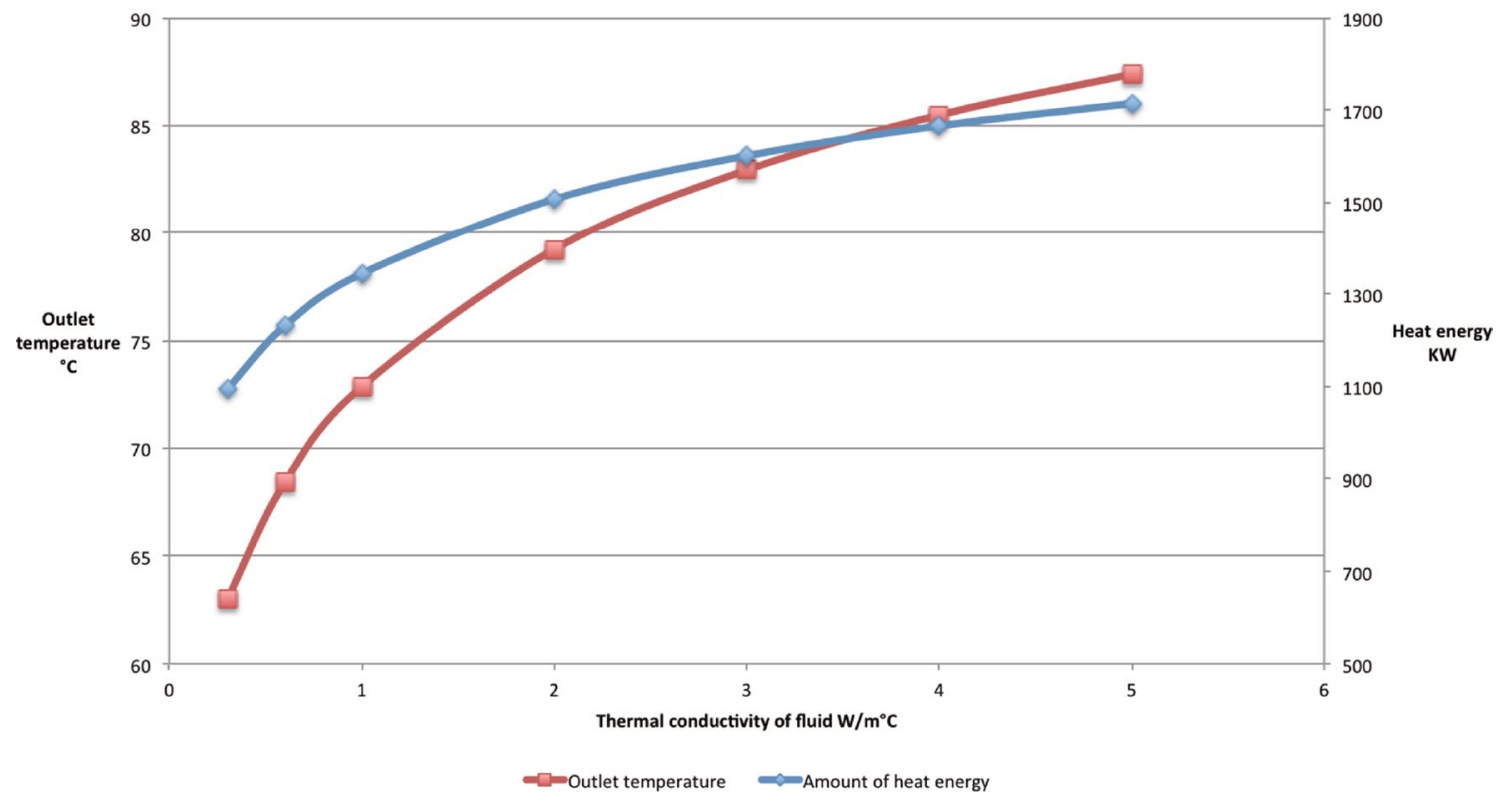

Fig. 3 Temperature and heat energy regarding working fluids' thermal conductivity

The fluid with higher thermal conductivity obviously gains more heat. As a result, the outlet temperature after one circulation increases as expected. Seemingly, the rate at which heat is obtained decreases for higher thermal conductivities, compared to the rate of increased temperature. The increase in thermal conductivity from $0.3 \frac{\mathrm{W}}{\mathrm{m}^{\circ} \mathrm{C}}$ to $5.0 \frac{\mathrm{W}}{\mathrm{m}^{\circ} \mathrm{C}}$ results in increase in the outlet temperature from 63.02 to $87.38^{\circ} \mathrm{C}$. Therefore, the thermal conductivity of fluids is a critical variable to affect the heat transfer in the wellbore.

\section{Specific heat capacity}

Specific heat capacity, defined as the amount of heat energy per unit mass required to raise the temperature by 


\section{Specific heat capacity of fluid}

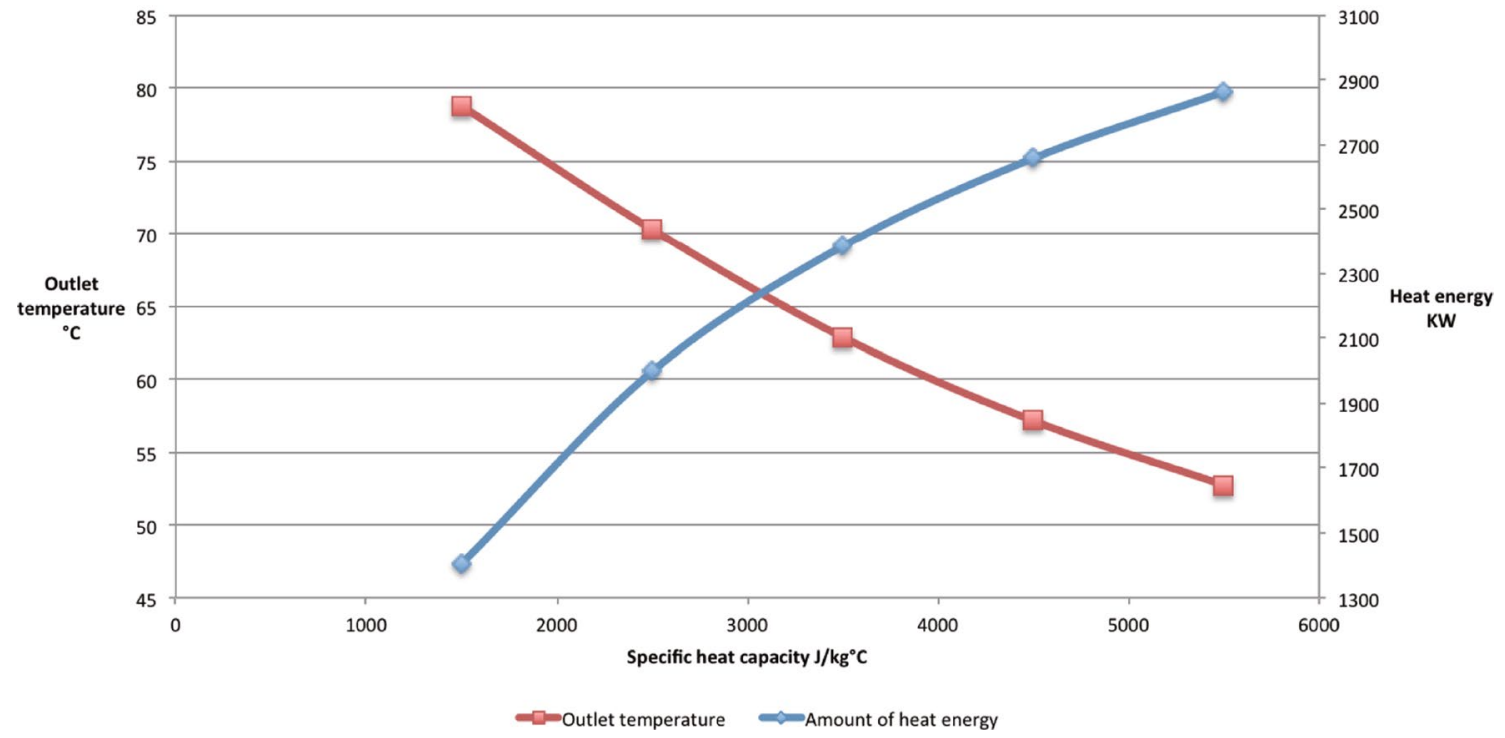

Fig. 4 Temperature and heat energy regarding working fluids' heat capacity

$1{ }^{\circ} \mathrm{C}$, is also a critical parameter to determine the heat transfer efficiency. Figure 4 shows the decrease of the outlet temperatures with the increase of specific heat capacity. An increase in specific heat capacity from $1500 \frac{J}{\mathrm{~kg}^{\circ} \mathrm{C}}$ to $5500 \frac{\mathrm{J}}{\mathrm{kg}^{\circ} \mathrm{C}}(267 \%)$ leads to a decrease of the outlet temperature from 79 to $53^{\circ} \mathrm{C}(33 \%)$. It is obvious that for the lower heat capacity yields more desirable outcome, in terms of higher outlet temperature, is achieved. However, an opposite trend exists for the heat energy gained, since the heat capacity is proportional to the heat. Therefore, consideration of thermophysical properties of working fluids is crucial when selecting the working fluid.

\section{Viscosity}

For any given fluid, viscosity has a major impact on the flow characteristics. It affects, for example, both the flow regime and pressure drop. In our study, viscosity also affects the convective heat transfer, as it is a parameter used in the calculation of Reynolds number and Prandtl number. Figure 5 shows that the viscosity has a huge impact on the outlet fluid temperature. As the viscosity increases, the outlet temperature is increasing towards higher and more desirable values. The variation is dramatic. For an increase between $0.005 P_{a} s$ and $0.1 P_{a} s$, the increase in temperature is $98.9 \%$. Since the increase in the outlet temperature has a great effect on the heat energy, the heat also increases as the fluid viscosity approaches higher values.

\section{Inlet temperature}

The temperature of the injected working fluid is important to its outlet values when the fluid returns after a full circulation. Inlet temperature needs to be optimally set regarding the proposed usage of the geothermal heat, whether it is for heating purposes or for generation of electricity. To attain higher outlet temperatures, often better suited for generation of electricity, one should consider higher inlet temperatures. Lower temperatures, however, increase the energy accumulated during the circulation, due to higher temperature difference between inlet and outlet temperature. Figure 6 shows that by increasing the inlet temperature from 0 to $60^{\circ} \mathrm{C}$, the outlet temperature increases linearly. An outlet temperature of $90.11^{\circ} \mathrm{C}$ can be achieved for the inlet temperature of $60^{\circ} \mathrm{C}$, and $71.93^{\circ} \mathrm{C}$ outlet temperature can be reached when the inlet temperature is $0^{\circ} \mathrm{C}$. The investigation of inlet temperatures for low temperatures like $0^{\circ} \mathrm{C}$ is used to describe the trend theoretically, which is not likely to be utilized in a commercial geothermal system. Normally the low inlet temperature is recommended to be used in applications.

\section{Discussions}

From the above sensitivity analysis on working fluids' properties, the design of the working fluids is important for the performance of the heat exchanger. Besides thermodynamic properties, other aspects should be taken into account such as thermal stability, toxicity, flammability and environmental impact to prevent damage to plants, limit costs related to operation and maintenance and to avoid hazards

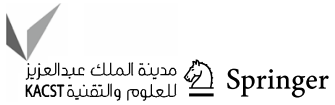




\section{Viscocity of fluid}

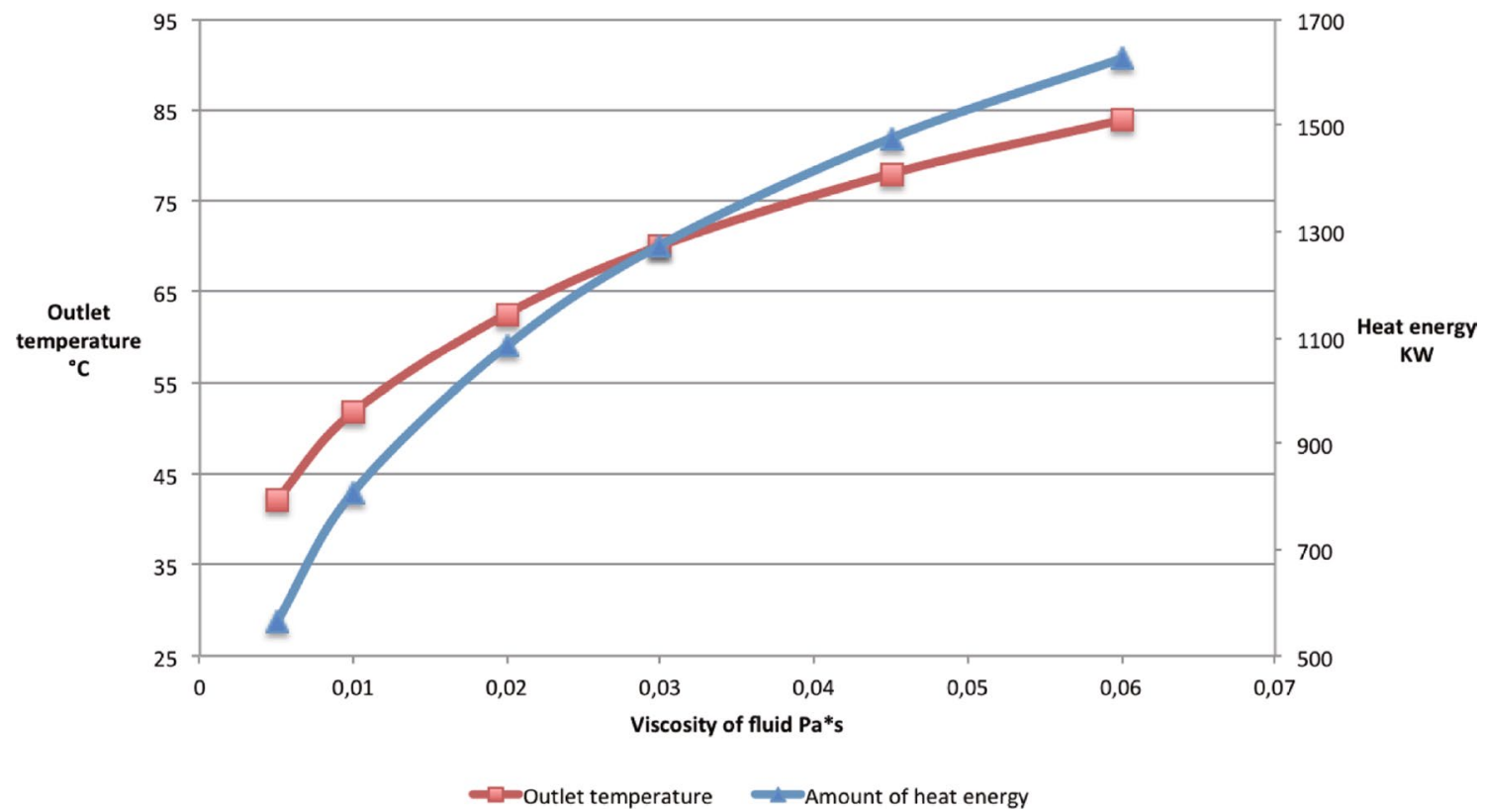

Fig. 5 Temperature and heat energy regarding working fluids' viscosity

\section{Inlet temperature}

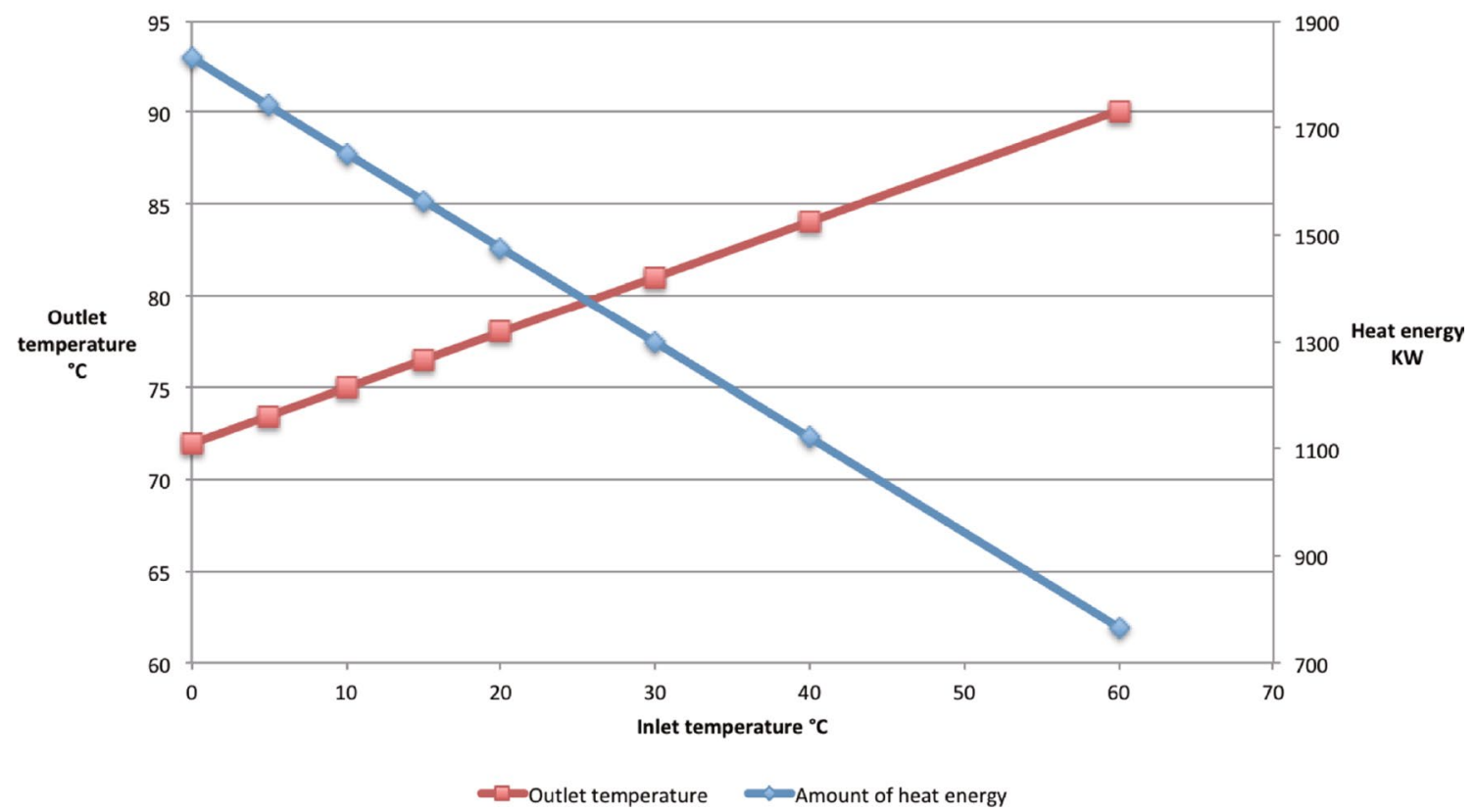

Fig. 6 Temperature and heat energy regarding working fluids' inlet temperature

for employees and for the natural environment (Astolfi et al. 2014). In their discussion, the working fluid design should also consider the geothermal gradient and the depth of the well. Several studies have been made regarding working fluids (Davis and Michaelides 2009; Bu et al. 2012; Cheng et al.
2013, 2014; Alimonti et al. 2016; Akhmadullin and Tyagi 2014). Conventionally the low-temperature resources, which are the case for abandoned oil and gas wells, have been used directly for district heating and for geothermal heat pumps. Traditionally water is used as working fluid for single cycle 
geothermal power plants. However, using organic fluids with lower boiling point than water, low-temperature geothermal energy can also be converted into electricity.

\section{Geostring}

\section{Geostring insulation}

Heat transfer through conduction is inevitable as the temperatures of the working fluids inside and outside the geostring are different, thus materials with low value of thermal conductivity are preferred for insulation purposes. Insulation is used to limit the heat flow between the outer and the inner pipes, so that the fluid flowing up the inner pipe keeps the heat. Another purpose of insulation is to prevent the heat loss from the circulating fluid to the formation, which might happen if the temperature of the inlet fluid is higher than the upper part of the well (Templeton 2013). Figure 7 shows the variation in the outlet fluid temperature and heat energy relative to different degrees of insulation on the geostring. An increase of approximately $182 \%$ in the outlet temperature is obtained as the insulation changes from $0.01 \frac{\mathrm{W}}{\mathrm{m}^{\circ} \mathrm{C}}$ to $0.00005 \frac{\mathrm{W}}{\mathrm{m}^{\circ} \mathrm{C}}$. To achieve such a large increase in output temperature by installing the effective insulation can be cost-efficient.

\section{Geostring diameter}

When a wellbore is drilled, its volume is fixed. The increase of the geostring diameter means that the geostring volume is increasing, whereas the annulus volume is decreasing. Smaller annulus volume results in the increased fluids velocity for the constant flow rate hence increased heat convection within the fluid. This implies that the fluid would gain more heat as it flows downwards. However, the velocity inside the geostring would decrease, due to the expansion of the geostring diameter. The fluid will then have longer time period to lose heat through the geostring wall. However, this fact will be compensated by the reduced convection losses accompanying the ascending fluid at a reduced velocity. Then, a proper insulation is important to prevent heat transferring from the geostring to the annulus. Figure 8 shows that the trend is towards a higher outlet temperature and more heat energy is extracted from the well when the diameter is increased.

\section{Discussions}

Pipes made of steel have a very high thermal conductivity. Therefore, to maximize the outlet temperature of the fluid, insulation with lower thermal conductivity should be added, see Fig. 7. There are two main purposes for the insulation. One is to limit the heat flow between the outer and inner pipe, so that the fluid flowing up the inner pipe lose less heat. The other one is to prevent heat loss from the fluid to the formation, which might happen if the temperature of the inlet fluid is higher than the upper part of the well. For best insulating effect air (Kujawa et al. 2006), magnesia (Nalla et al. 2005) or polystyrene (Davis and Michaelides 2009) might be used. Normally the outlet temperature is improved for thicker insulation. However, as the well was already drilled, thicker insulation would mean a reduction either in the radius of annulus or the inner pipe. From Fig. 8 the reduction of radius leads

Thermal conductivity of insulation

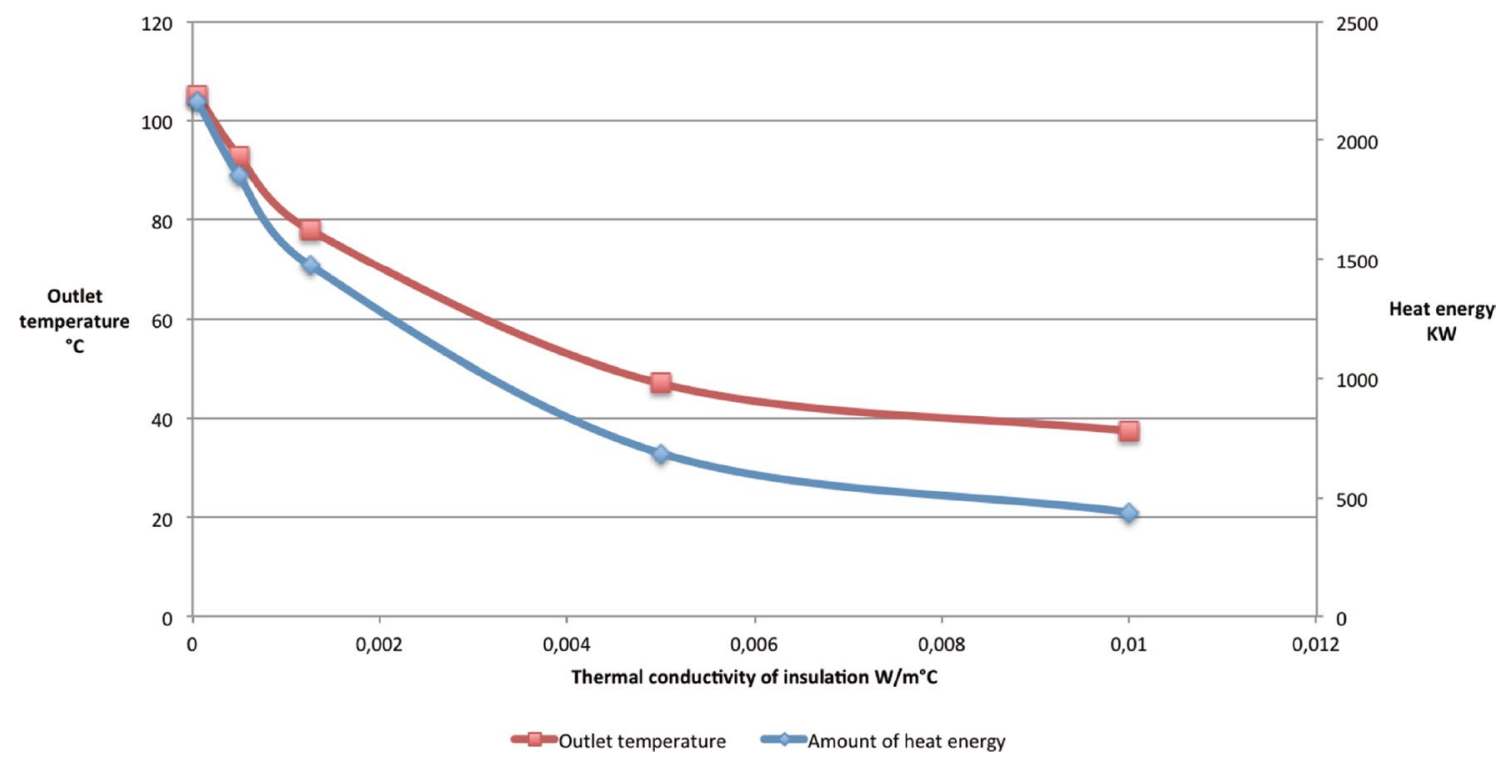

Fig. 7 Temperature and heat energy regarding thermal conductivity of insulation 


\section{Geostring diameter}

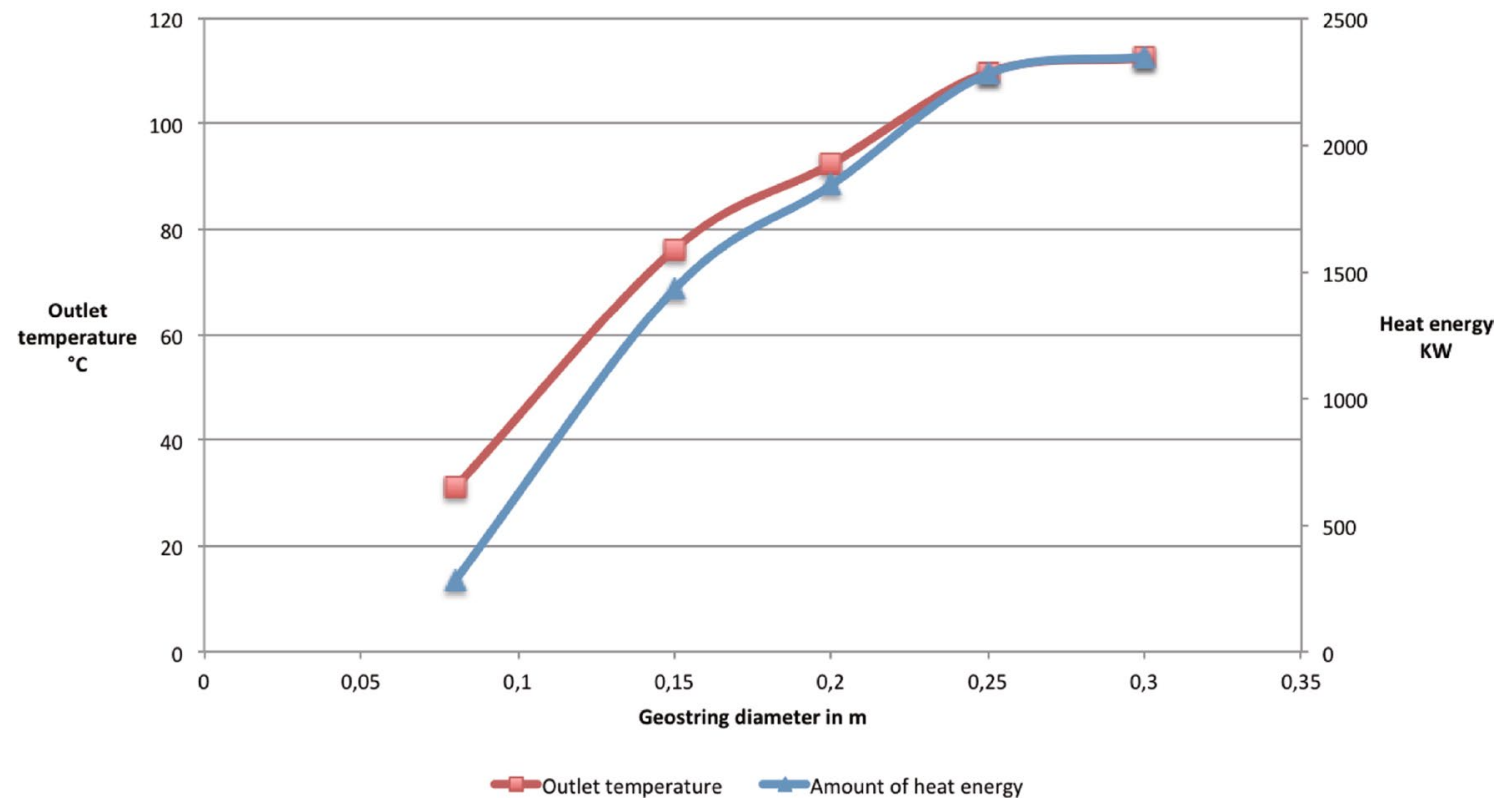

Fig. 8 Temperature and heat energy regarding diameter of the geostring

to lower outlet temptation. Moreover, the thicker insulation might result in a lower injection rate and an increase of the velocity. Consequently, the pumping power required would increase, resulting in lower net power.

\section{Conclusion}

In this paper, we investigated the nature of geothermal energy, by conducting a comprehensive literature review on this topic and looked into the possibilities of energy extraction from abandoned petroleum wells as a more economical way comparing to the dedicated geothermal wells. A heat transfer process from formation to the working fluid inside the geostring through multiple interfaces (formation/annular region, annular region/geostring wall, geostring wall/working fluid) is modeled. This approach gives information about how much heat can be extracted from the formation comparing to the most commonly used assumption of negligible thermal resistance of these interfaces. We have also performed an extensive sensitivity study to determine the optimal operational parameters during working fluid circulation. Because the location of abandoned petroleum wells to be redesigned is predefined, and all geology-related parameters are known, in our analysis, we focused on the effect of thermophysical and transport properties of the working fluid. The study shows that both the outlet temperature and the total energy increase significantly with the increase of viscosity and thermal conductivity. At the other hand, fluid density variation did not affect the theoretical amount of geothermal heat that can be extracted from the reservoir in the case study. The specific heat capacity increased the total heat energy produced, but decreased the temperature of the return fluid. The working fluids composition should also be considered as a potentially important factor that affects the well performance, which, however, was not a part of the current study. The outlet temperature naturally increased for higher inlet temperatures, whereas the rate of increase was lower than the magnitude of the outlet temperature increase, which indicated that the process optimization has to be done with respect to other parameters. A higher inner diameter of the geostring provided more beneficial output due to the increased heat convection within the fluid. Finally, geostring insulation made of material with low thermal conductivity is preferred due to its ability to preserve accumulated heat and prevent it from dissipation.

Acknowledgements Authors would like to thank for financial support through the Plogen program.

Open Access This article is distributed under the terms of the Creative Commons Attribution 4.0 International License (http://creativeco mmons.org/licenses/by/4.0/), which permits unrestricted use, distribution, and reproduction in any medium, provided you give appropriate credit to the original author(s) and the source, provide a link to the Creative Commons license, and indicate if changes were made.

\section{Appendix A}

The wellbore is discretized along the vertical direction and the radial direction, respectively, into small cells. In the vertical axis, the Taylor expansion of the first derivative is 
Fig. 9 Temperature and heat energy regarding diameter of the geostring

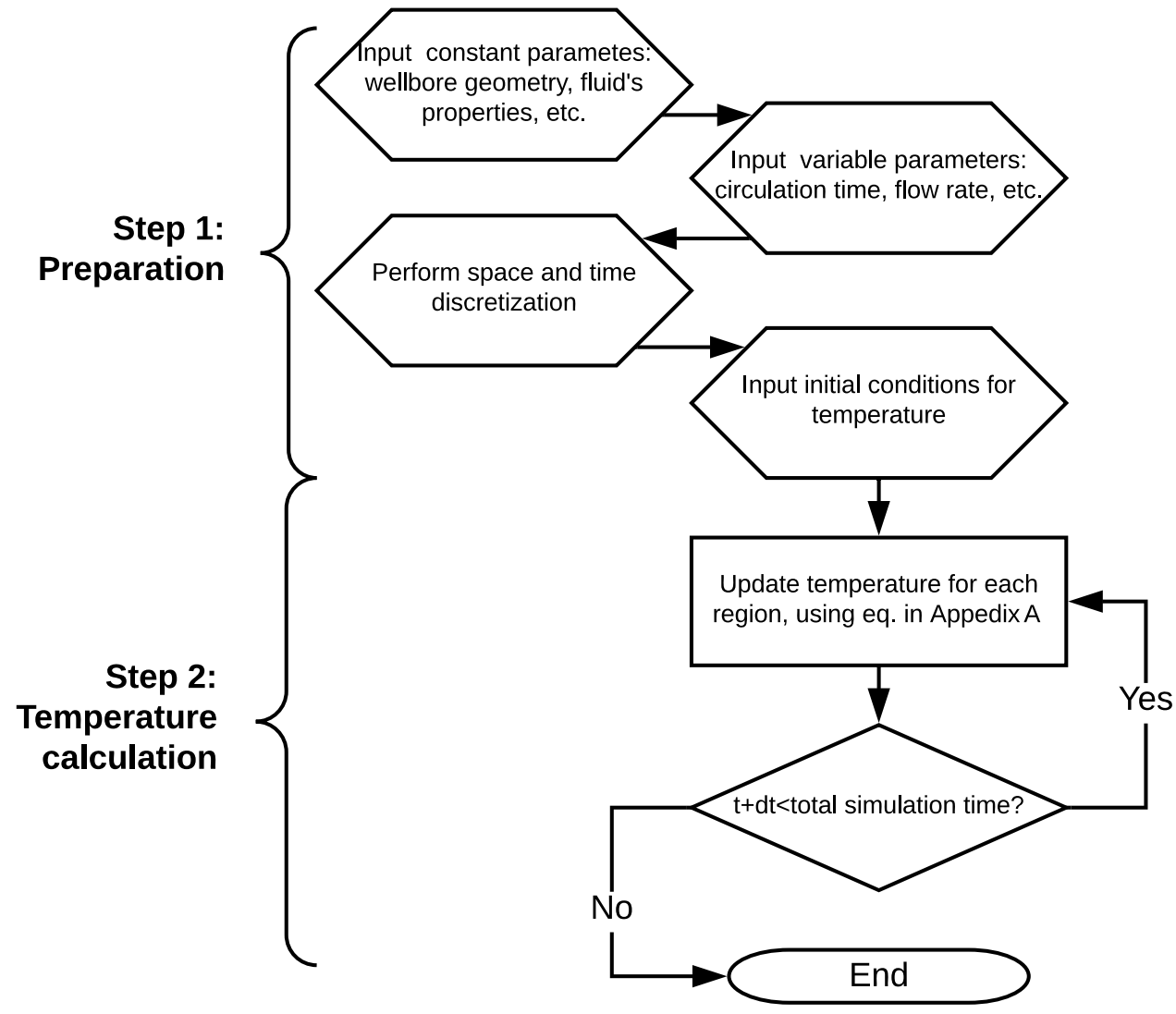

(9)

$\frac{\partial T}{\partial t} \approx \frac{T_{(i, j)}^{t+\Delta t}-T_{(i, j)}^{t}}{\Delta t}$

where $T_{i, j}^{t}$ is the temperature in the cell $(i, j)$ at the past time. Applying the above Eqs. (9)-(13) for each region, a generalized formula could be derived at $(i, j)$ cell;

$\Theta(i, j) T_{(i+1, j)}^{t+\Delta t}+\Upsilon(i, j) T_{(i, j)}^{t+\Delta t}+\Gamma(i, j) T_{(i-1, j)}^{t+\Delta t}+\Phi(i, j) T_{(i, j+1)}^{t+\Delta t}$
$\quad+\Psi(i, j) T_{(i, j-1)}^{t+\Delta t}=\Omega(i, j) T_{(i, j)}^{t}$,

where $\Theta(i, j), \Upsilon(i, j), \Gamma(i, j), \Phi(i, j), \Psi(i, j)$ and $\Omega(i, j)$ are coefficient vectors. Following the numerical method in SantoyoGutirrez (1997), in the first half of a time step $t+\Delta t / 2$, the above equation is solved in one direction in an implicit form and in other direction in an explicit from. In the second half of the time step, the former explicit direction is changed to an implicit form and the other direction is changed to an explicit form. The flow chart is given in Fig. 9.

\section{Appendix B}

Table 2 summarizes all parameters used in the simulation. The wellbore architecture is shown in Fig. 10. time discretization at cell $(i, j)$ is given by 
Table 2 Parameters used in the simulation

\begin{tabular}{|c|c|c|}
\hline Parameter & Predifined value & Denotion \\
\hline Outer diameter of geostring & 0.161 & $m$ \\
\hline Thickness of geostring & 0.01 & $m$ \\
\hline Thickness of casing tube & 0.01 & $m$ \\
\hline Diameter of wellbore & 1.0604 & $m$ \\
\hline Diameters of casing tubes & $0.624 ; 0.7397 ; 0.9080$ & $m$ \\
\hline Fluid flowrate & 15.9 & $\frac{\mathrm{kg}}{\mathrm{g}}$ \\
\hline Geothermal gradient & 0.03 & $\frac{{ }^{\circ} \mathrm{C}}{m}$ \\
\hline Surface temperature & 15.3 & ${ }^{\circ} \mathrm{C}$ \\
\hline Inlet fluid temperature & 20 & ${ }^{\circ} \mathrm{C}$ \\
\hline Fluid density & 1200 & $\frac{\mathrm{kg}}{\mathrm{m}^{3}}$ \\
\hline $\begin{array}{l}\text { Specific heat capacity of working } \\
\text { fluid }\end{array}$ & 1600 & $\frac{J}{\mathrm{~kg}^{\circ} \mathrm{C}}$ \\
\hline $\begin{array}{l}\text { Thermal conductivity of working } \\
\text { fluid }\end{array}$ & 1.75 & $\frac{W}{m^{\circ} \mathrm{C}}$ \\
\hline Viscosity of working fluid & 0.045 & $P_{a} s$ \\
\hline Formation density & 2640 & $\frac{\mathrm{kg}}{\mathrm{m}^{3}}$ \\
\hline Specific heat capacity of formation & 800 & $\frac{J}{\mathrm{~kg}^{\circ} \mathrm{C}}$ \\
\hline Thermal conductivity of formation & 2.25 & $\frac{W}{m^{\circ} \mathrm{C}}$ \\
\hline Density of cement & 3140 & $\frac{\mathrm{kg}}{\mathrm{m}^{3}}$ \\
\hline Specific heat capacity of cement & 2000 & $\frac{J}{\mathrm{~kg}^{\circ} \mathrm{C}}$ \\
\hline Thermal conductivity of cement & 0.7 & $\frac{W}{m^{\circ} \mathrm{C}}$ \\
\hline Density of insulation & 1.225 & $\frac{\mathrm{kg}}{\mathrm{m}^{3}}$ \\
\hline $\begin{array}{l}\text { Specific heat capacity of insula- } \\
\text { tion }\end{array}$ & 1000 & $\frac{J}{\mathrm{~kg}^{\circ} \mathrm{C}}$ \\
\hline Thermal conductivity of insulation & 0.00125 & $\frac{W}{m^{\circ} \mathrm{C}}$ \\
\hline Section length & $600 ; 900 ; 1500 ; 1500$ & $m$ \\
\hline
\end{tabular}

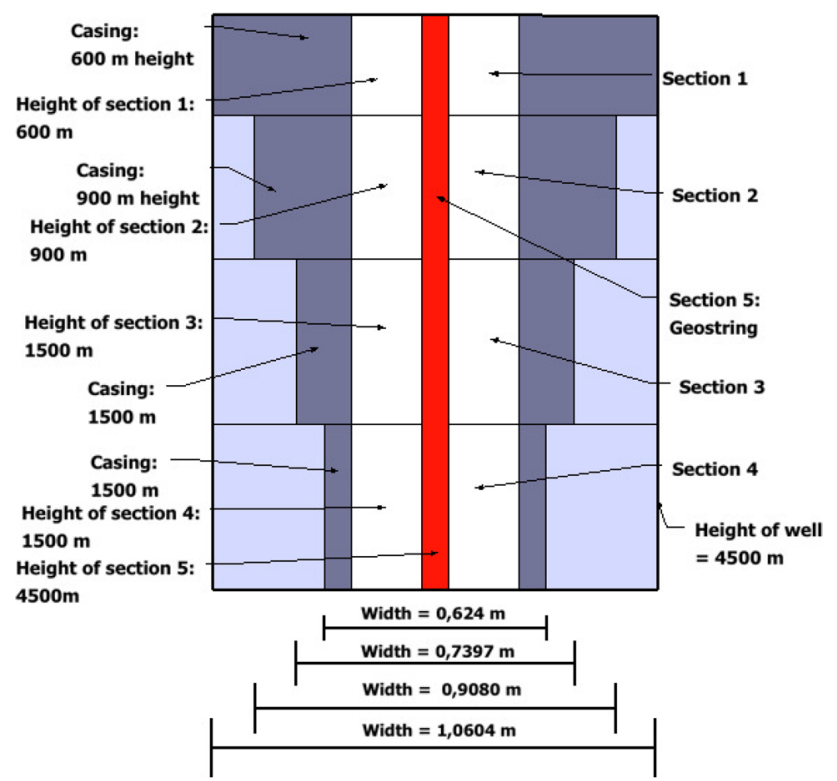

\section{References}

Ahmadi M, Dahi Taleghani A (2016) Feasibility study of heat extraction from a closed-loop fractured geothermal reservoir; a multiphysics problem. In: 50th U.S. Rock Mechanics/Geomechanics Symposium, American Rock Mechanics Association, Houston, Texas

Akhmadullin I, Tyagi M (2014) Design and analysis of electric power production unit for low enthalpy geothermal reservoir applications. Int J Mech Mechatron Eng 8(6):443-449

Alimonti C, Soldo E (2016) Study of geothermal power generation from a very deep oil well with a wellbore heat exchanger. Renewable energy 86:292-301

Astolfi M, Romano MC, Bombarda P, Macchi E (2014) Binary orc (organic rankine cycles) power plants for the exploitation of mediumlow temperature geothermal sources part b: Technoeconomic optimization. Energy 66:435-446

Barbacki A (2000) The use of abandoned oil and gas wells in Poland for recovering geothermal heat. In: Proceedings world geothermal congress, pp 3361-3365

Barbier E (2002) Geothermal energy technology and current status: an overview. Renew Sustain Energy Rev 6:3-65

Bergman Theodore L, Incropera Frank P, DeWitt David P, Lavine Adrienne S (2011) Fundamentals of heat and mass transfer. Wiley, Hoboken

Bu X, Ma W, Li H (2012) Geothermal energy production utilizing abandoned oil and gas wells. Renew Energy 41:80-85

Cheng WL, Li TT, Nian YL, Wang CL (2013) Studies on geothermal power generation using abandoned oil wells. Energy 59:248-254

Cheng W-L, Li T-T, Nian Y-L, Xie K (2014) Evaluation of working fluids for geothermal power generation from abandoned oil wells. Appl Energy 118:238-245

Clauser C, Ewert M (2018) The renewables cost challenge: levelized cost of geothermal electric energy compared to other sources of primary energy review and case study. Renew Sustain Energy Rev 82:3683-3693

Davis AP, Michaelides EE (2009) Geothermal power production from abandoned oil wells. Energy 34:866-872

Dittus FW, Boelter LMK (1930) Heat transfer in automobile radiators of the tubular type. Publ Eng Univ Calif Berk 2:443

Feng M (2011) The temperature prediction in deepwater drilling of vertical well. $\mathrm{PhD}$ thesis, Texas $\mathrm{A}$ and M University

Geothermal energy association-geothermal basics (2014). Retrieved from 2018. http://www.geo-energy.org/basics.aspx

Ghoreishi-Madiseh SA, Hassani FP, Al-Khawaja MJ (2012) A novel technique for extraction of geothermal energy from abandoned oil wells. In: World renewable energy forum

Ghoreishi-Madiseh SA, Templeton J, Hassani F, Al-Khawaja MJ, Aflaki E (2014) Geothermal energy extraction from decommissioned petroleum wells. ISRM International Symposium-8th Asian rock mechanics symposium. International Society for Rock Mechanics and Rock Engineering, Sapporo

Gnielinski V (1976) New equations for heat and mass transfer in the turbulent pipe and channel flow. Int Chem Eng 16(2):359-368

Kabir CS, Hasan AR, Kouba GE, Ameen M (1996) Determining circulating fluid temperature in drilling, workover, and well control operations. SPE Drill Complet 11:74-79

Karstad E (1999) Time-dependent temperature behavior in rock and borehole. PhD thesis, University of Stavanger

Kharseh M, Al-Khawaja M, Hassani F (2015) Utilization of oil wells for electricity generation: performance and economics. Energy 90:910-916

Fig. 10 Different sections with depth and width 
Kujawa T, Nowak W, Stachel AA (2005) Analysis of the exploitation of existing deep production wells for acquiring geothermal energy. J Eng Phys Thermophys 78:127-135

Kujawa T, Nowak W, Stachel AA (2006) Utilization of existing deep geological wells for acquisitions of geothermal energy. Energy 31:650-664

Kujbus A (2007) Mol geothermal power plant project—new segment in the hungarian geothermal exploration. In: Proceedings European geothermal congress

Kurevija T, Vulin D (2011) High enthalpy geothermal potential of the deep gas fields in central Drava basin, Croatia. Water Resour Manage 25:30413052

Livescu S, Wang X (2014) Analytical downhole temperature model for coiled tubing operations. In: SPE coiled tubing and well intervention conference and exhibition

Lund JW, Freeston DH, Boyd TL (2005) World-wide direct uses of geothermal energy 2005. In: Proceedings world geothermal congress

Lund JW, Freeston DH, Boyd TL (2011) Direct utilization of geothermal energy 2010 worldwide review. Geothermics 40(3):159-180

Lund JW, Boyd TL (2015) Direct utilization of geothermal energy 2015 worldwide review. In: Proceedings world geothermal congress, pp 1-31

Mock JE, Tester JW, Wright PM (1997) Geothermal energy from the earth: its potential impact as am environmentally sustainable resource. Annu Rev Energy Environ 22:305-356

Nalla G, Shook GM, Mines GL, Bloomfield KK (2005) Parametric sensitivity study of operating and design variables in wellbore heat exchangers. Geothermics 34:330-346
Reyes A (2007) Abandoned oil and gas wells—a reconnaissance study of an unconventional geothermal resource. Avalon: GNS Science Report

Roksland M, Basmoen TA, Sui D (2016) Geothermal energy extraction from abandoned wells. In: The 8th international conference on applied energy

Santoyo-Gutirrez ER (1997) Transient numerical study simulation of heat transfer processes during drilling of gheothermal wells. $\mathrm{PhD}$ thesis, University of Salford

Sanyal SK, Butler SJ (2010) Geothermal power capacity from petroleum wellssome case histories of assessment. In: Proceedings world geothermal congress

Sieder EN, Tate GE (1936) Heat transfer and pressure drop of liquids in tubes. Ind Eng Chem 28(12):1429-1435

Templeton JD, Ghoreishi-Madiseh SA, Hassani F (2014) Abandoned petroleum wells as sustainable sources of geothermal energy. Energy 70:366-373

Templeton J (2013) Abandoned petroleum wells as sustainable/renewable sources of geothermal energy. Master thesis in Department of Mining and Materials Engineering, McGill University, Canada

Wei Y, Wang F, Ren B (2009) Drainage and production by using geothermal in Huabei oil region. Oil Drill Product Technol 31:93-95

Wight NM, Bennet NS (2015) Geothermal energy from abandoned oil and gas wells using water in combination with a closed wellbore. Appl Therm Eng 89:908-915

Publisher's note Springer Nature remains neutral with regard to jurisdictional claims in published maps and institutional affiliations. 